\title{
Evaluation of Chemical Use and Storage at an Industrial Electrical Supply Company
}

Karl D. Feldmann, MS, CIH

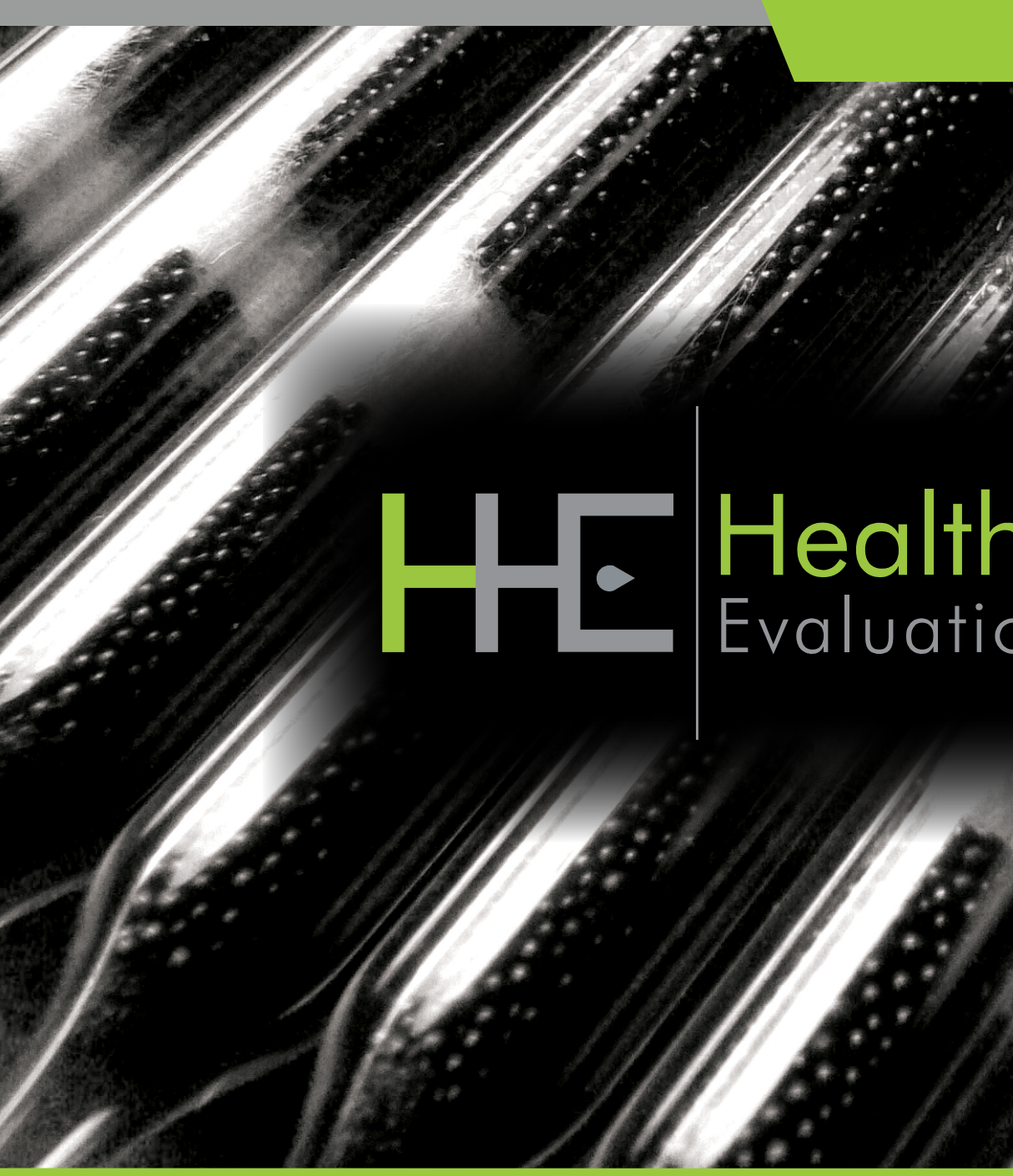

HHE Report No. 2014-0152-3236

May 2015 Melody M. Kawamoto, MD, MS-OM 


\section{Contents}

Highlights.............................................i

Abbreviations ................................... iii

Introduction .................................... 1

Methods ................................................... 1

Results and Discussion ........................ 2

Conclusions ........................................ 9

Recommendations........................... 10

Appendix $\ldots \ldots \ldots \ldots \ldots \ldots \ldots \ldots \ldots \ldots \ldots \ldots \ldots \ldots \ldots \ldots$

References....................................... 14

Acknowledgements........................... 17

The employer is required to post a copy of this report for 30 days at or near the workplace(s) of affected employees. The employer must take steps to ensure that the posted report is not altered, defaced, or covered by other material.

The cover photo is a close-up image of sorbent tubes, which are used by the HHE Program to measure airborne exposures. This photo is an artistic representation that may not be related to this Health Hazard Evaluation. Photo by NIOSH. 


\section{Highlights of this Evaluation}

The Health Hazard Evaluation Program received a request to evaluate an industrial electronic and electrical supply company in Texas. Managers were concerned about potential exposures from the use of laser marking spray and about chemical storage at the facility.

\section{What We Did}

- We evaluated the facility in June 2014.

- We reviewed health and safety programs and related documents.

- We observed work processes, practices, and conditions.

- We took general area air samples for volatile organic compounds.

- We confidentially interviewed warehouse, assembly, and shipping/receiving employees about their work, possible exposures to workplace hazards, and health concerns.

\section{What We Found}

- The company had started developing and implementing programs to improve occupational safety and health.

- Some chemicals were improperly stored and labeled.

- Local exhaust and general ventilation systems were inadequate.

- Respirators were used and stored improperly.

- Soldering work for the company was being done in homes of employees with young children.

We observed work practices, interviewed employees, reviewed documents, and inspected the ventilation systems at an electrical supply company. Although the company had begun developing and implementing occupational safety and health programs, we found areas in need of improvement. We recommended improvement/addition of local exhaust ventilation systems and compliance with Occupational Safety and Health Administration Hazard Communication Program requirements. We also recommended ending take-home work that could cause hazardous exposures to occupants in the home.

\section{What the Employer Can Do}

- Install local exhaust ventilation systems for the soldering and laser marking spray stations.

- Improve the local exhaust ventilation for the laser marker/cutter.

- Improve the general air handling systems by providing outdoor air to the occupied areas.

- Follow the Occupational Safety and Health Administration Hazard Communication Standard.

- Perform a job hazard analysis for jobs and tasks of concern. 
- Do not give employees take-home work that could cause hazardous exposures to occupants in the home.

- Create a health and safety committee with employer and employee representatives.

- Properly label and store chemicals.

\section{What Employees Can Do}

- Wash your hands with soap and water before eating, drinking, smoking, using the bathroom, and leaving work.

- Do not eat or drink in areas where hazardous substances may be present.

- Tell your supervisor if you have work-related health and safety problems or concerns. 


\section{Abbreviations}

CFR Code of Federal Regulations

HSE Health, Safety, and Environment

NIOSH National Institute for Occupational Safety and Health

OEL Occupational exposure limit

OSHA Occupational Safety and Health Administration 
This page left intentionally blank 


\section{Introduction}

The Health Hazard Evaluation Program received a request from the Director of Health, Safety, and Environment (HSE) at an industrial electronic and electrical supply company. The request was prompted by an International Organization for Standardization 9001 audit of the company that raised concerns about occupational health and safety, including chemical storage and possible hazardous exposures. We visited the company's offices and warehouse in June 2014. We conducted a walk-through survey of the office, warehouse, shipping/ receiving, and assembly areas; privately interviewed employees; collected area air samples; and reviewed health and safety program documents. We provided a letter detailing our evaluation and preliminary recommendations to employee and employer representatives in July 2014.

\section{Process Description}

The company's offices and warehouse occupy a 19,300 square-foot building constructed in 1999. In 2012, the company added 4,400 square feet of space for inventory storage, and built a mezzanine-level assembly department above the shipping/receiving area. A small lunch area was located in the office.

The company sells industrial electrical and electronic supplies, wire lubricant, thread-lock adhesive, and custom-made wiring harnesses. Employee work tasks included the following:

- Resizing and repackaging industrial wire and electronic connectors for resale

- Repackaging lubricants and thread lock adhesive for resale

- Hand-assembling custom wiring harnesses

- Hand-soldering electric components

- Spraying a water-based aerosol to electrical connectors prior to marking them with a laser/cutter

\section{Methods}

Our objectives were to evaluate potential workplace exposures and managerial and employee awareness about occupational safety and health. We achieved this by observing work practices and procedures; collecting general area air samples for volatile organic compounds in each of the work areas; reviewing workplace programs, procedures, and practices; and confidentially interviewing employees.

\section{Workplace Observations}

We looked at employee work practices and visually inspected the air-handling units and the local exhaust ventilation system attached to the laser marker/cutter. We asked about housekeeping practices and general maintenance schedules. 


\section{Air Sampling}

We collected general area air samples in the office, warehouse, shipping/receiving, and assembly areas for volatile organic compounds using thermal desorption tubes following National Institute for Occupational Safety and Health (NIOSH) Method 2549 [NIOSH 2015]. We also collected area air samples on charcoal tubes following NIOSH Method 1500 [NIOSH 2015]. On the basis of the qualitative thermal desorption tube analyses, we quantitatively analyzed the charcoal tube samples for limonene, toluene, cyclohexane, and xylene.

\section{Program and Document Review}

We reviewed the following records:

- Hazard communication, respiratory protection, and laser safety programs

- Manufacturer safety data sheets for commonly used chemicals

- Occupational Safety and Health Administration (OSHA) Form 300, Log of Work-related Injuries and Illnesses

\section{Employee Interviews}

We confidentially interviewed all 14 assembly, shipping, and warehouse employees who were at work at the time of our evaluation. We asked them about their work, possible exposures to workplace hazards, occupational safety and health training and practices, and health concerns. Because we learned about take-home work when we were preparing for our visit, we asked them about take-home work and children in the home. We also asked about children in the workplace.

\section{Results and Discussion}

\section{Workplace Observations}

\section{General Workplace Activities}

Employees in the shipping/receiving area resized wire from spools, repackaged electrical connectors, and packaged custom wiring assemblies made in-house for shipment. We did not see employees using products or chemicals that contained toluene or limonene but we did find an old bottle of solvent that contained toluene in the shipping/receiving area. Because this solvent was no longer used the bottle was removed and flagged for disposal. Employees used laser marking spray in the office file room before moving this activity to a small balcony outside the assembly area (discussed later in this section). We saw no visible evidence of previous spray activities in the file room.

Prior to our evaluation the company had replaced on-site bulk chemical mixing with purchasing of prepackaged containers of electrical lubricants and thread lock adhesive directly from the manufacturers. As a result of this change the company had already disposed of some bulk chemicals, and more disposal activities were planned. Some unused chemicals 
had been collected and stored in a designated area in the warehouse. We have since learned from company managers that these items have been disposed. Other chemicals no longer used or sold by the company (some with broken seals and faded labels) remained on shelves in the warehouse awaiting the next round of disposal. The warehouse had one storage cabinet for flammable materials. Because it did not have enough space for all of the flammable chemicals in use or awaiting disposal, a newly designated chemical storage room was being organized (Figure 1).

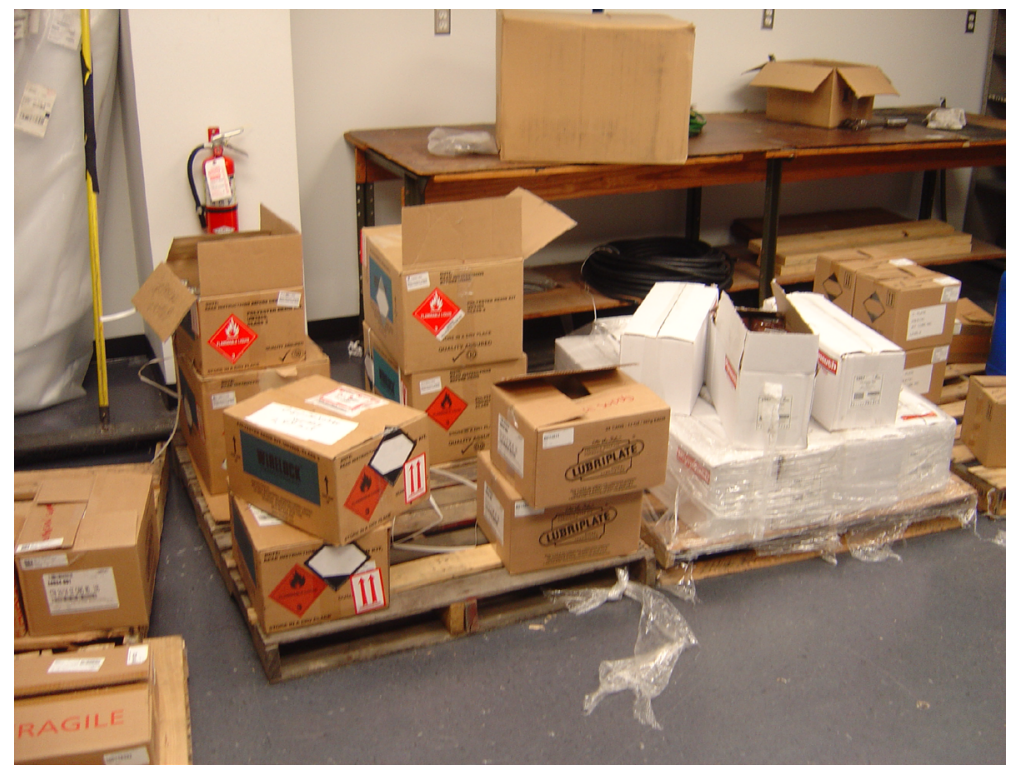

Figure 1. Chemical storage room. Photo by NIOSH.

Employees occasionally used a propane-powered fork lift in the warehouse. The fork lift had been recently serviced but no established preventative maintenance program was in place. Employees reported fork lift use was infrequent.

Applying laser marking spray and soldering activities can generate air contaminants. However, in our opinion, airborne exposures would be negligible because these activities were infrequent and of short duration. Thus, we took area samples but not personal breathing zone samples during these activities.

We saw chemicals in unlabeled containers or repurposed containers without proper labeling. We also saw flammable materials stored outside of the designated storage areas for flammable materials. Signs prohibiting eating were recently posted in work areas, except in the office area where eating was allowed. We did not see employees eating or drinking in the warehouse and assembly areas but we saw employees drinking beverages in the shipping/ receiving area. A vending machine that was too large for the lunch area was located in the shipping/receiving area. 


\section{Laser Marker and Cutter}

The company used an enclosed laser marker and cutter to mark electrical connectors by melting and bonding marking spray pigments onto the surface of the connector. A flexible duct connected the laser marker and cutter enclosure to an exhaust fan on the mezzanine, and a rigid vent ran from the fan through the roof; there was no filtration system. On rare occasions, employees used the laser marker and cutter to cut acrylic sheeting into part trays. This activity did not occur during our evaluation but employees mentioned noticing an odor during acrylic cutting but not during laser marking. The presence of odor could be the result of the enclosure not being adequately sealed or insufficient local exhaust ventilation.

\section{Laser Marking Spray}

Employees intermittently applied water-based laser marking spray from an aerosol can to electrical connectors in a balcony next to the mezzanine-level assembly room. This area was not designed as a work area. Flexible ventilation ducts hanging from the ceiling and lying on the floor restricted employee movement and the duct on the floor created a trip hazard (Figure 2). The table where the employee applied the laser marking spray had no local exhaust ventilation. Overspray could enter the warehouse area below the balcony and be mixed with the general ventilation. The employee wore clear safety glasses, nitrile gloves, and a non-permeable apron. The company did not require respiratory protection when spraying, but we saw one employee voluntarily wearing an elastomeric half-mask respirator with organic vapor cartridges. The spraying activity we observed lasted about 3 minutes and occurred only once that day.

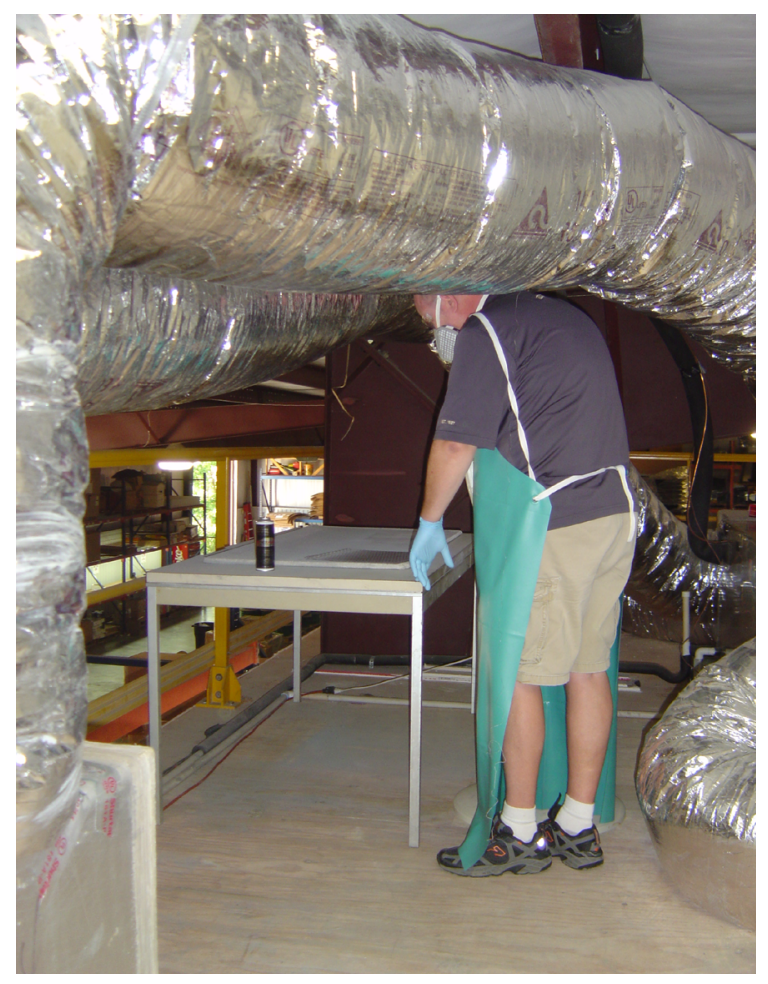

Figure 2. Applying laser marking spray to parts. Photo by $\mathrm{NIOSH}$. 


\section{Soldering}

In the assembly area, we saw one employee soldering electrical connectors to the end of a cable by hand (Figure 3). The employee wore clear safety glasses but no gloves or respiratory protection. The employee used a small vise attached to the workstation to hold the parts being soldered. The soldering iron was thermostatically controlled, with the tip temperature adjusted according to the solder being used. The type of solder and lead content was selected by the customer, with silver solder used most of the time. The duration that the employee soldered was based on the needs of the day's production schedule and typically did not last the entire work shift. There was no local exhaust in the assembly area.

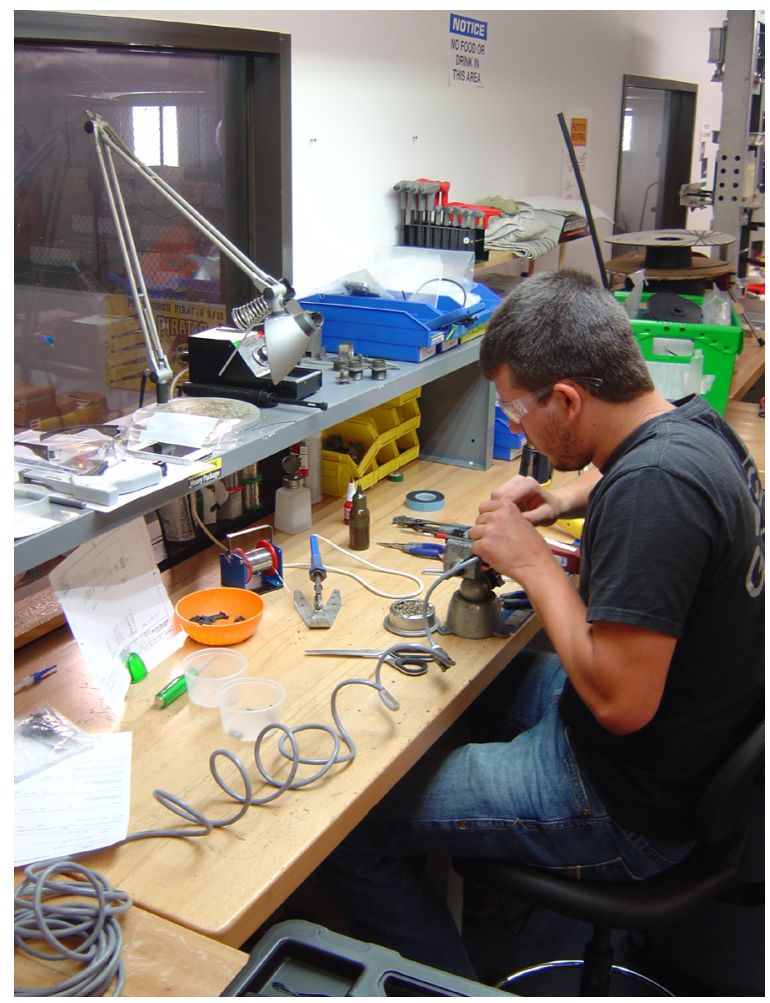

Figure 3. An employee working at the soldering station. Photo by $\mathrm{NIOSH}$. 


\section{Ventilation}

The company's recirculating, residential-style heating and air-conditioning systems did not bring outdoor air into the building. The units were thermostatically controlled. Two of the three wall-mounted exhaust fans in the warehouse were partially blocked by boxes

(Figure 4). Employees switched these fans on each morning at 7:30 a.m. and off at the end of the workday at 4:30 p.m.

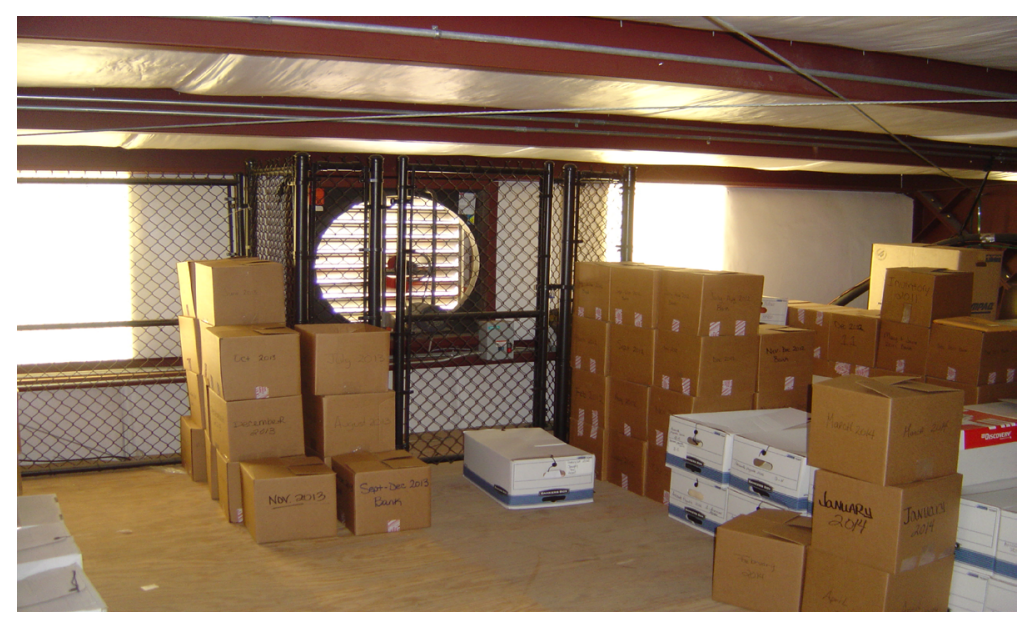

Figure 4. Boxes stacked around a warehouse exhaust fan. Photo by NIOSH.

Using smoke tubes, we found that the warehouse was under negative pressure, meaning air moved into the warehouse from adjacent areas such as the chemical storage room, the shipping/receiving room, and the assembly areas.

All but one of the air filters used in the ventilation systems were pleated paper; the remaining one was fiberglass media. The company changed the filters monthly and recorded this in a log, but no other scheduled maintenance plan existed for these ventilation systems. Air filters in some areas appeared clean, but filters in the chemical storage room were visibly dirty.

We saw standing water in the condensate drip pan of one of the air conditioner units. This could be caused by an insufficiently sloped drip pan or a clogged condensate drain. We were told that the heating, ventilation, and air-conditioning unit for the new chemical storage room served that room only.

\section{Program and Document Review}

\section{Hazard Communication Program}

The company had no written hazard communication program. The HSE director had begun to implement certain aspects of a hazard communication program such as:

- Posting signs about not eating or drinking at workstations

- Conducting monthly safety meetings 
- Addressing chemical storage issues by:

$\bigcirc$ designating a dedicated chemical storage room

$\bigcirc$ identifying and segregating unneeded chemicals for proper disposal

○ moving flammable chemicals into a chemical storage cabinet designed for flammable materials

- contacting suppliers to change product packaging to minimize employee exposures

\section{Respiratory Protection Program}

The company did not have a written respiratory protection program, but some employees used NIOSH-approved respirators voluntarily. The company provided these employees with the respiratory protection of their choice. We observed two instances of respirator use during our visit:

- An employee wore a disposable N95 filtering facepiece respirator while applying a water-based latex paint with a brush.

- An employee wore an elastomeric half-mask respirator with organic vapor cartridges while spraying laser marking paint.

Particulate prefilters were available for the elastomeric respirator but not used. We showed the employee how to use the prefilters. When not in use, this respirator was not stored according to manufacturer's guidelines.

\section{Laser Safety Program}

The company had no written laser safety program. However, the company only used a class 3R laser marker and cutter in the assembly department to mark parts for internal tracking. The American National Standards Institute defines class 3R laser systems as potentially hazardous under some direct and reflected viewing conditions but this type of laser system is considered safe if handled carefully. An enclosed class 3R laser with restricted beam viewing, like the one used at this company, does not require a written laser safety program [ANSI 2004]. This laser marker and cutter was enclosed and only functioned when the lid was closed.

\section{Safety Data Sheet Review}

We reviewed product safety data sheets with the HSE director. Products included solder wire, aerosol dry lubricant, aerosol electrical parts degreaser, soldering flux remover, and a waterbased laser marking spray. The HSE director was concerned about the aerosol laser marking spray. The safety data sheet for this marking spray recommended the use of safety glasses or goggles, chemical resistant gloves, and appropriate respiratory protection when exposure to airborne contaminants were likely to exceed occupational exposure limits (OELs). The safety data sheet also recommended local exhaust ventilation to keep concentrations below acceptable OELs. 


\section{Log of Work-Related Injuries and Illnesses}

The HSE director reported that OSHA Form 300 logs of work-related injuries and illnesses were not available before 2014 and that no recordable incidents had been reported in recent years. We found no recorded incidents in our review of the company's 2014 OSHA Form 300. The HSE director informed us about a work-related injury that had not been reported at the time of the incident. He had appropriately contacted OSHA for guidance on how to record the injury.

\section{Air Sampling}

Table 1 presents the results of the area air sampling for limonene and toluene, two of the four predominant compounds identified in the qualitative thermal desorption tube screening. The other two predominant compounds, cyclohexane and xylene, were not detected. Limonene and toluene concentrations were less than 2 parts per million. We did not detect the chemicals listed in the laser marking spray safety data sheet (i.e., acetone, ethanol, propane) in these area air samples.

Table 1. Area air sampling results (in parts per million)

\begin{tabular}{lcc}
\hline Sample location & Limonene & Toluene \\
\hline Office & $(0.84)$ & $\mathrm{ND}$ \\
Shipping/Receiving & 1.9 & $(0.46)$ \\
Warehouse & $\mathrm{ND}$ & $\mathrm{ND}$ \\
Assembly & $\mathrm{ND}$ & $\mathrm{ND}$ \\
\hline Minimum detectable concentration & 0.29 & 0.41 \\
Minimum quantifiable concentration & 1.8 & 1.2 \\
\hline
\end{tabular}

Concentrations shown in parentheses are above the minimum concentration that can be detected but below the minimum concentration that can be quantified. This means that there is more uncertainty associated with these concentrations.

$\mathrm{ND}=$ Not detected, concentrations were below the minimum detectable concentration (shown above based on a 25 liter air sample).

\section{Employee Interviews}

We confidentially interviewed 14 employees with job titles in sales, assembly, shipping/ receiving, warehouse, and the HSE director. All but one employee reported working in more than one area of the facility. Almost all worked in or entered the shipping/receiving area and the warehouse; more than half spent at least part of their workday in the assembly area. Although more than half of the employees entered the chemical storage area, they entered the room only rarely and for short periods of time. At the time of our visit, employees reported the following types of work: seven assembled cables, six spooled wire, one performed laser marking and cutting, and one performed soldering. Four employees reported that, in the past, they rebottled liquid chemicals but only rarely. 
Employees reported working in or near areas with possible exposures to soldering fumes, laser marking spray, lead wire, liquid chemicals, contaminants from laser marking and cutting, Teflon ${ }^{\circledR}$ coating released during wire stripping, dry molybdenum lubricant spray for the spooling machine, and forklift exhaust. Six employees reported that some of their work involved repeated rapid movements, force, or awkward positions: two from lifting heavy items, two from computer work (typing and mouse use), one during wire spooling, and one unspecified. The only health concerns reported were metallic taste and the possibility of family exposures (such as lead related to take-home soldering work and other exposures related to children in the workplace).

Assembly work that involved lead soldering was done at two homes occupied by young children. Because lead exposure often occurs with no obvious symptoms, it frequently goes unrecognized. Young children are particularly susceptible. Contamination at home may not be easy to clean. The company had changed to a solder with a lower percentage of lead but the new solder still contained lead. Although we cannot say whether or how much contamination could be happening in an employee's home and the surrounding environment, soldering is a source of contamination that could affect the health of occupants in the home. NIOSH and OSHA have information on how children could be affected by lead and what can be done to prevent contamination at home [NIOSH 2013; OSHA 2014]. Children rarely visited the workplace and, when they did, they mostly stayed in the office area.

Employees reported that:

- Monthly meetings with occupational safety and health training began several months before our visit to the facility. Occupational safety and health training topics included safety data sheets, personal protective equipment, lifting, forklift safety, chemical safety, fire extinguisher use, and dangers of texting while driving.

- They no longer ate in work areas where food and hands might have been contaminated by workplace chemicals. All employees reported washing their hands before eating.

- They handled spools of lead wire only when pulling orders for shipment. They did not remove lead wire from the spools.

\section{Conclusions}

Under the direction of the recently hired HSE director, the company has started to develop and implement programs and practices to improve occupational safety and health. Examples include monthly occupational safety and health training; moving activities that generated air contaminants away from occupied areas; no longer allowing eating in potentially contaminated areas; and disposing unused chemicals. On the basis of our area air sampling results and the intermittent use of laser marking spray, personal exposures to limonene, toluene, acetone, ethanol, and propane should likely be well below OELs. However, soldering without local exhaust ventilation may contribute to lead exposure and contamination of the workplace. Additionally, take-home soldering work may be a source of childhood lead exposure. 


\section{Recommendations}

On the basis of our findings, we recommend the actions listed below. We encourage the industrial electrical supply company to use a labor-management health and safety committee or working group to discuss our recommendations and develop an action plan. Those involved in the work can best set priorities and assess the feasibility of our recommendations for the specific situation at the electrical supply company.

Our recommendations are based on an approach known as the hierarchy of controls (see Appendix). This approach groups actions by their likely effectiveness in reducing or removing hazards. In most cases, the preferred approach is to eliminate hazardous materials or processes and install engineering controls to reduce exposure or shield employees. Until such controls are in place, or if they are not effective or feasible, administrative measures and personal protective equipment may be needed.

\section{Engineering Controls}

Engineering controls reduce employees' exposures by removing the hazard from the process or by placing a barrier between the hazard and the employee. Engineering controls protect employees effectively without placing primary responsibility of implementation on the employee.

1. Install local exhaust ventilation systems for the soldering station and laser marking spray station, and improve the local exhaust ventilation for the laser marker and cutter. The local exhaust ventilation systems should not recirculate potentially contaminated exhaust air back into the work areas and should have sufficient air velocity to control the hazard (dust or vapor). The air handling systems providing general ventilation to the remaining occupied areas should deliver an adequate amount of outdoor air with the recirculated air. We recommend consulting with a qualified ventilation engineer.

2. Ensure that existing HVAC systems are functioning as designed and appropriate for the work performed in each zone. The design(s) should also control temperature and relative humidity levels within thermal comfort guidelines [ANSI/ASHRAE 2013a,b].

3. Relocate or redesign the laser marking spray area to improve employee movement and eliminate the tripping hazards.

\section{Administrative Controls}

The term administrative controls refers to employer-dictated work practices and policies to reduce or prevent hazardous exposures. Their effectiveness depends on employer commitment and employee acceptance. Regular monitoring and reinforcement are necessary to ensure that policies and procedures are followed consistently.

1. Start a written Hazard Communication Program that includes a chemical inventory, annual training, and other elements required by OSHA. OSHA publishes a useful document "Hazard Communication - Small Entity Compliance Guide for Employers That Use Hazardous Chemicals.” See https://www.osha.gov/Publications/OSHA3695.pdf. 
2. Perform a job hazard analysis for tasks using chemicals. A job hazard analysis is a systematic risk assessment to identify likely workplace hazards and ways to eliminate or reduce them. You can learn more about conducting a job hazard analysis at the following OSHA website: https://www.osha.gov/Publications/osha3071.pdf?utm source $=$ rss\&utm medium $=$ rss\&utm_campaign=job-hazard-analysis- 13 .

3. Label and store chemicals properly.

4. Comply with OSHA requirements about recording work-related injuries and illnesses on the OSHA log.

5. Do not give employees take-home work that could cause hazardous exposures to occupants in the home.

\section{Personal Protective Equipment}

Personal protective equipment is the least effective means for controlling hazardous exposures. Proper use of personal protective equipment requires a comprehensive program and a high level of employee involvement and commitment. The right personal protective equipment must be chosen for each hazard. Supporting programs such as training, changeout schedules, and medical assessment may be needed. Personal protective equipment should not be the sole method for controlling hazardous exposures. Rather, personal protective equipment should be used until effective engineering and administrative controls are in place.

1. Select respirators on the basis of the hazards that employees may be exposed to. If you decide that employees can voluntarily wear filtering facepiece respirators, the employee must be provided a copy of Appendix D of the OSHA Respiratory Protection Standard [29 CFR 1910.134] titled "Information for Employees Using Respirators When Not Required Under the Standard." For all other voluntary users (such as those wearing half-mask elastomeric respirators), an additional written respirator program that covers medical fitness and proper maintenance procedures must be implemented. The OSHA Small Entity Compliance Guide provides guidance on voluntary respirator use and additional information on respiratory protection at https://www.osha.gov/Publications/3384small-entity-for-respiratory-protectionstandard-rev.pdf. 


\section{Appendix: Occupational Exposure Limits}

NIOSH investigators refer to mandatory (legally enforceable) and recommended OELs for chemical, physical, and biological agents when evaluating workplace hazards. OELs have been developed by federal agencies and safety and health organizations to prevent adverse health effects from workplace exposures. Generally, OELs suggest levels of exposure that most employees may be exposed to for up to 10 hours per day, 40 hours per week, for a working lifetime, without experiencing adverse health effects. However, not all employees will be protected if their exposures are maintained below these levels. Some may have adverse health effects because of individual susceptibility, a pre-existing medical condition, or a hypersensitivity (allergy). In addition, some hazardous substances act in combination with other exposures, with the general environment, or with medications or personal habits of the employee to produce adverse health effects. Most OELs address airborne exposures, but some substances can be absorbed directly through the skin and mucous membranes.

Most OELs are expressed as a time-weighted average exposure. A time-weighted average refers to the average exposure during a normal 8- to 10-hour workday. Some chemical substances and physical agents have recommended short-term exposure limit or ceiling values. Unless otherwise noted, the short-term exposure limit is a 15-minute time-weighted average exposure. It should not be exceeded at any time during a workday. The ceiling limit should not be exceeded at any time.

In the United States, OELs have been established by federal agencies, professional organizations, state and local governments, and other entities. Some OELs are legally enforceable limits; others are recommendations.

- The U.S. Department of Labor OSHA permissible exposure limits (29 CFR 1910 [general industry]; 29 CFR 1926 [construction industry]; and 29 CFR 1917 [maritime industry]) are legal limits. These limits are enforceable in workplaces covered under the Occupational Safety and Health Act of 1970.

- NIOSH recommended exposure limits are recommendations based on a critical review of the scientific and technical information and the adequacy of methods to identify and control the hazard. NIOSH recommended exposure limits are published in the NIOSH Pocket Guide to Chemical Hazards [NIOSH 2010]. NIOSH also recommends risk management practices (e.g., engineering controls, safe work practices, employee education/training, personal protective equipment, and exposure and medical monitoring) to minimize the risk of exposure and adverse health effects.

- Other OELs commonly used and cited in the United States include the threshold limit values, which are recommended by American Conference of Governmental Industrial Hygienists, a professional organization, and the workplace environmental exposure levels, which are recommended by the American Industrial Hygiene Association, another professional organization. The threshold limit values and workplace environmental exposure levels are developed by committee members of these associations from a review of the published, peer-reviewed literature. These OELs are not consensus standards. Threshold limit values are considered voluntary exposure 
guidelines for use by industrial hygienists and others trained in this discipline "to assist in the control of health hazards" [ACGIH 2015]. WEELs have been established for some chemicals "when no other legal or authoritative limits exist" [AIHA 2014].

Outside the United States, OELs have been established by various agencies and organizations and include legal and recommended limits. The Institut für Arbeitsschutz der Deutschen Gesetzlichen Unfallversicherung (Institute for Occupational Safety and Health of the German Social Accident Insurance) maintains a database of international OELs from European Union member states, Canada (Québec), Japan, Switzerland, and the United States. The database, available at http://www.dguv.de/ifa/Gefahrstoffdatenbanken/GESTIS-InternationaleGrenzwerte-für-chemische-Substanzen-limit-values-for-chemical-agents/index-2.jsp, contains international limits for more than 1,500 hazardous substances and is updated periodically.

OSHA requires an employer to furnish employees a place of employment free from recognized hazards that cause or are likely to cause death or serious physical harm [Occupational Safety and Health Act of 1970 (Public Law 91-596, sec. 5(a)(1))]. This is true in the absence of a specific OEL. It also is important to keep in mind that OELs may not reflect current health-based information.

When multiple OELs exist for a substance or agent, NIOSH investigators generally encourage employers to use the lowest OEL when making risk assessment and risk management decisions. NIOSH investigators also encourage use of the hierarchy of controls approach to eliminate or minimize workplace hazards. This includes, in order of preference, the use of (1) substitution or elimination of the hazardous agent, (2) engineering controls (e.g., local exhaust ventilation, process enclosure, dilution ventilation), (3) administrative controls (e.g., limiting time of exposure, employee training, work practice changes, medical surveillance), and (4) personal protective equipment (e.g., respiratory protection, gloves, eye protection, hearing protection). Control banding, a qualitative risk assessment and risk management tool, is a complementary approach to protecting employee health. Control banding focuses on how broad categories of risk should be managed. Information on control banding is available at http://www.cdc.gov/niosh/topics/ctrlbanding/. This approach can be applied in situations where OELs have not been established or can be used to supplement existing OELs. 


\section{References}

ACGIH [2015]. 2015 TLVs ${ }^{\circledR}$ and BEIs ${ }^{\circledR}$ : threshold limit values for chemical substances and physical agents and biological exposure indices. Cincinnati, OH: American Conference of Governmental Industrial Hygienists.

AIHA [2014]. AIHA 2014 Emergency response planning guidelines (ERPG) \& workplace environmental exposure levels (WEEL) handbook. Fairfax, VA: American Industrial Hygiene Association.

ANSI (American National Standards Institute) [2004]. ANSI Z136.1-2004, American national standard for safe use of lasers. New York, New York: American National Standards Institute.

ANSI/ASHRAE [2013a]. Thermal environmental conditions for human occupancy. American National Standards Institute/ASHRAE standard 55-2013. Atlanta, GA: American Society for Heating, Refrigerating, and Air-Conditioning Engineers, Inc.

ANSI/ASHRAE [2013b]. Ventilation for acceptable indoor air quality. American National Standards Institute/ASHRAE standard 62.1-2013. Atlanta, GA: American Society of Heating, Refrigerating, and Air-Conditioning Engineers, Inc.

CFR. Code of Federal Regulations. Washington, DC: U.S. Government Printing Office, Office of the Federal Register.

NIOSH [2010]. NIOSH pocket guide to chemical hazards. Cincinnati, OH: U.S. Department of Health and Human Services, Centers for Disease Control and Prevention, National Institute for Occupational Safety and Health, DHHS (NIOSH) Publication No. 2010-168c. [http://www.cdc.gov/niosh/npg/]. Date accessed: May 2015.

NIOSH [2013]. NIOSH topic page: lead. Information for workers: how you can keep yourself and your family safe from lead. [http://www.cdc.gov/niosh/topics/lead/safe.html]. Date accessed: May 2015.

NIOSH [2015]. NIOSH manual of analytical methods (NMAM®). 4th ed. Schlecht PC, O'Connor PF, eds. Cincinnati, OH: U.S. Department of Health and Human Services, Centers for Disease Control and Prevention, National Institute for Occupational Safety and Health, DHHS (NIOSH) Publication 94-113 (August 1994); 1st Supplement Publication 96-135; 2nd Supplement Publication 98-119; 3rd Supplement 2003-154. [http://www.cdc.gov/niosh/ docs/2003-154/]. Date accessed: May 2015.

OSHA [2014]. OSHA quick card. If you work around lead, don't take it home! [https://www. osha.gov/Publications/OSHA3680.pdf]. Date accessed: May 2015. 
Keywords: North American Industry Classification System 423610 (Electrical Apparatus and Equipment, Wiring Supplies, and Related Equipment Merchant Wholesalers), Texas, volatile organic compounds, electric power distribution, electrical supplier, electrical assembly, laser marking, soldering, local exhaust ventilation, chemical storage, safety culture, take-home work. 
This page left intentionally blank 
The Health Hazard Evaluation Program investigates possible health hazards in the workplace under the authority of the Occupational Safety and Health Act of 1970 (29 U.S.C. § 669(a) (6)). The Health Hazard Evaluation Program also provides, upon request, technical assistance to federal, state, and local agencies to investigate occupational health hazards and to prevent occupational disease or injury. Regulations guiding the Program can be found in Title 42, Code of Federal Regulations, Part 85; Requests for Health Hazard Evaluations (42 CFR Part 85).

\section{Disclaimer}

The recommendations in this report are made on the basis of the findings at the workplace evaluated and may not be applicable to other workplaces.

Mention of any company or product in this report does not constitute endorsement by NIOSH.

Citations to Web sites external to NIOSH do not constitute NIOSH endorsement of the sponsoring organizations or their programs or products. NIOSH is not responsible for the content of these Web sites. All Web addresses referenced in this document were accessible as of the publication date.

\section{Acknowledgments}

Analytical Support: Jennifer Roberts, Bureau Veritas North America

Desktop Publisher: Shawna Watts

Editor: Ellen Galloway

Logistics: Donnie Booher, Kevin Moore

Medical Field Assistance: Dr. Talib Ali, MD, MPH

\section{Availability of Report}

Copies of this report have been sent to the employer and employees at the facility. The state and local health department and the Occupational Safety and Health Administration Regional Office have also received a copy. This report is not copyrighted and may be freely reproduced.

This report is available at http://www.cdc.gov/niosh/hhe/reports/pdfs/2014-0152-3236.pdf.

\section{Recommended citation for this report:}

NIOSH [2015]. Health hazard evaluation report: evaluation of chemical use and storage at an industrial electrical supply company. By Feldmann KD, Kawamoto MM. Cincinnati, OH: U.S. Department of Health and Human Services, Centers for Disease Control and Prevention, National Institute for Occupational Safety and Health, NIOSH HHE Report No. 2014-0152-3236. 
Delivering on the Nation's promise:

Safety and health at work for all people through research and prevention

To receive NIOSH documents or more information about occupational safety and health topics, please contact NIOSH:

Telephone: 1-800-CDC-INFO (1-800-232-4636)

TTY: 1-888-232-6348

CDC INFO: www.cdc.gov/info

or visit the NIOSH Web site at www.cdc.gov/niosh

For a monthly update on news at $\mathrm{NIOSH}$, subscribe to

$\mathrm{NIOSH}$ eNews by visiting www.cdc.gov/niosh/eNews. 